$$
\text { DOE/PC/92550--16 }
$$

Fiftinth Quarterly Technical Progress Report

(April 1-June 28,1996)

\title{
EVALUATION OF HYPERBARIC FILTRATION FOR FINE COAL DEWATERING
}

DOE Grant No. DE-FG22-92PC92550

By

B.K.Parekh (PI)

University of Kentucky

R.Hogg (Co-PI)

The Pennsylvania State University

FIETREITTAN AE THE DOCIMENT IS UNLMITER.Fonseca(Co-PI)

Consol Inc. 


\section{DISCLAMMER}

Portions of this document may be illegible in electronic image products. Images are produced from the best available original document. 


\section{DISCLAIMER}

This report was prepared as an account of work sponsored by an agency of the United States Government. Neither the United States Government nor any agency thereof, nor any of their employees, make any warranty, express or implied, or assumes any legal liability or responsibility for the accuracy, completeness, or usefulness of any information, apparatus, product, or process disclosed, or represents that its use would not infringe privately owned rights. Reference herein to any specific commercial product, process, or service by trade name, trademark, manufacturer, or otherwise does not necessarily constitute or imply its endorsement, recommendation, or favoring by the United States Government or any agency thereof. The views and opinions of authors expressed herein do not necessarily state or reflect those of the United States Government or any agency thereof. 


\section{DISCLAIMER}

Portions of this document may be illegible in electronic image products. Images are produced from the best available original document. 


\section{OBJECTIVES AND SCOPE OF WORK}

The main objectives of the project are to investigate the fundamental aspects of particle-liquid interaction in fine coal dewatering, to conduct laboratory and pilot plant studies on the applicability of hyperbaric filter systems and to develop process conditions for dewatering of fine clean coal to less than 20 percent moisture.

The program consist of three phases, namely

$\begin{array}{lll}\text { Phase I } & - & \text { Model Development } \\ \text { Phase II } & - & \text { Laboratory Studies } \\ \text { Phase III } & - & \text { Field Testing }\end{array}$

The Pennsylvania State University is leading efforts in Phase I, the University of Kentucky in Phase II, and Consol Inc. in Phase III of the program. All three organizations are involved in all the three phases of the program. The Pennsylvania State University is developing a theoretical model for hyperbaric filtration systems, whereas the University of Kentucky is conducting experimental studies to investigate fundamental aspects of particle-

$\therefore$ liquid interaction and application of high pressure filter in fine coal dewatering. The optimum filtration conditions identified in Phase I and II will be tested in a Consol Inc. coal preparation plant using an Andritz Ruthner portable hyperbaric filtration unit.

\section{INTRODUCTION}

Most of the coal presently used by the utility industry is cleaned at preparation plants employing wet processes. Water, while being the mainstay of coal washing, is also one of the least desirable components in the final product. Coarse coal $(+3 / 4$ inch $)$ is easily dewatered to a 3-4 percent moisture level using conventional vibrating screens and centrifuges. However, 
the main problem of excess product moisture occurs in fine (minus 28 mesh) coal and refuse. Even though fines may constitute only about 20 percent of a contemporary cleaning plant feed, they account for two-thirds of the product surface moisture. This high surface moisture offsets many of the benefits of coal cleaning, and can easily undercut the ongoing programs on recovery of fine clean from refuse as well as producing an ultra-fine super clean coal fuel.

Currently, most of the coal preparation plants utilize vacuum disk or drum filter technology for dewatering of the fine coal, providing dewatered product containing about 25 percent moisture. The coal industry would prefer to have a product moisture in the range of 10 to 15 percent. Although the desired product quality can be obtained using thermal dryer, there are problems associated with this technology such as high capital costs and a source of air pollution.

In the present research project, an alternative to thermal drying, hyperbaric filtration which has shown potential in lowering moisture content in fine coal to less than 20 percent level, is being investigated in detail. The project will develop fundamental information on

$\therefore$ particle-liquid interaction during hyperbaric filtration and apply the knowledge in developing optimum conditions for the pilot plant testing of the hyperbaric filter system.

\section{Phase I- Model Developement:}

A final report on this phase of the program is being prepared. The major conclusions drawn are as follows.

Generalized models for continuous hyperbaric filtration have been developed using the classical model for constant pressure filtration as a starting point. Specific models have been developed and evaluated for:

- cake formation and filter capacity

- cake dewatering: residual saturation and air consumption 
Emphasis has been placed on the role of cake structure in the filtration process. Since detailed analysis of cake structure is only possible post priori, and by no means simple even then, we have concentrated primarily on the use of simplified structure models in which the pore structure in the cake is predicted from a knowledge of the characteristics of the feed particles.

It has been shown that the simplest structure model, in which pores are treated as a set of uniform capillaries with a single effective circular radius, cannot uniquely represent a pore size distribution. The distribution of pore sizes has a dominant effect on fluid (water or air) flow through the cake and on residual moisture content. Pore shape is also important but its effects appear to be less significant than those of size distribution. Our evaluation of shape effects suggest that it is probably reasonable, in most cases, to combine size and shape effects into a single distribution of effective pore radii.

Materials such as clean coal do not generally form compressible filter cakes, yet measured flow resistances show some attributes (e.g., pressure effects) of compressible cakes. We have proposed a binary packing model in which the finest particles in the feed (which may often be subject to agglomeration) form an inner, open-structured and potentially compressible layer within the main cake structure. Pressure effects and the role of flocculants, etc., can be ascribed to modifications of this layer.

While the major objective of this research program has been to investigate mechanical dewatering by hyperbaric filtration, the possible role of evaporation has also been evaluated. Based on a simplified model for evaporative dewatering, it has been concluded that this mechanism probably plays a negligible role under normal (i.e., ambient temperature) conditions. It could, however, be a principal mechanism at elevated temperatures, e.g., in steam filtration. 


\section{Phase II Laboratory Studies:}

The laboratory studies results for the Illinois No.6, Pittsburgh No. 8, and Pocahontas No.3 clean coal slurries are summarized in Figures 1,2, and 3, respectively.

For the Illinois slurry, the vacuum filtration provided a 24.8 percent moisture; whereas high pressure ( 60 psi or 4 bar) filtration provided 21.8 percent moisture filter cake. Addition of either $115 \mathrm{~g} / \mathrm{t}$ of an anionic flocculant; or $1.5 \mathrm{Kg} /$ ton of a cationic surfactant provided the lowest 17 percent moisture in the filter cake, which is about 20 percent relative moisture reduction over that obtained with high pressure filter without addition of reagents and 31 percent relative moisture reduction over the filter cake moisture obtained using the vacuum filter.

For the Pittsburgh No. 8 coal slurry (Figure 32), the vacuum filter produces a 73 percent moisture product due to the very fine size particles, while the hyperbaric filter using 70 psi ( 4.8 bars) pressure reduces the moisture to 24 percent. The combined use of various types of enhancement approaches reduces the moisture to 10.5 percent. The final moisture reduction achieved is 56 percent over the baseline moisture obtained using the hyperbaric filtration alone. For the Pocahontas No. 3 coal slurry (Figure 3 ), vacuum filtration provides a 24 percent moisture product, which is close to that obtained in the preparation plants processing the Pocahontas No. 3 coal. Hyperbaric filter using 80 psi (5.5 bar) pressure reduces the moisture to 11 percent, a more than 50 percent relative moisture reduction. The use of the combined dewatering enhancement approaches reduces the moisture to as low as 4.85 percent, which is a 56 percent relative moisture reduction over the baseline moisture obtained using the hyperbaric filter and an 80 percent relative moisture reduction over the filter cake moisture obtained using the vacuum filter. 


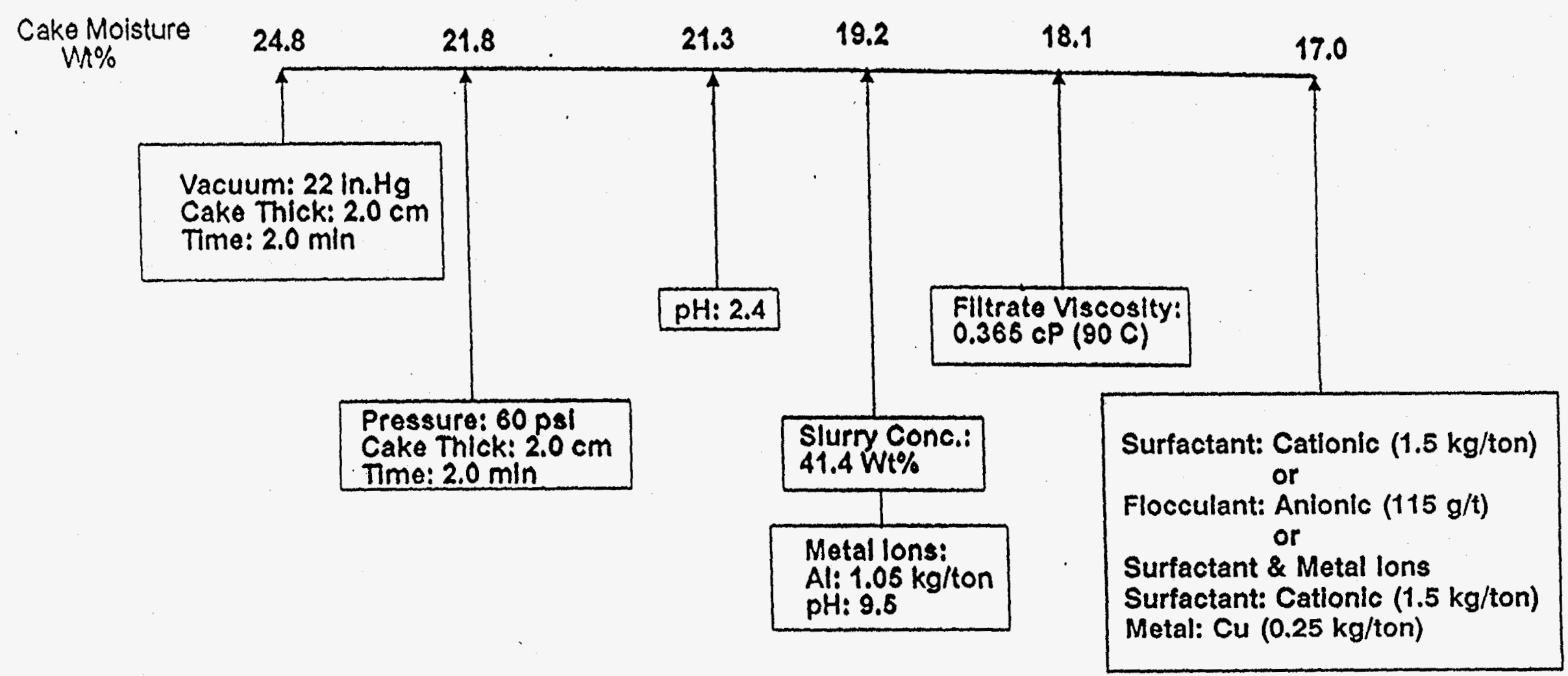

Figure 1. Summary of laboratory dewatering results for the Illinois No.6 froth product. 


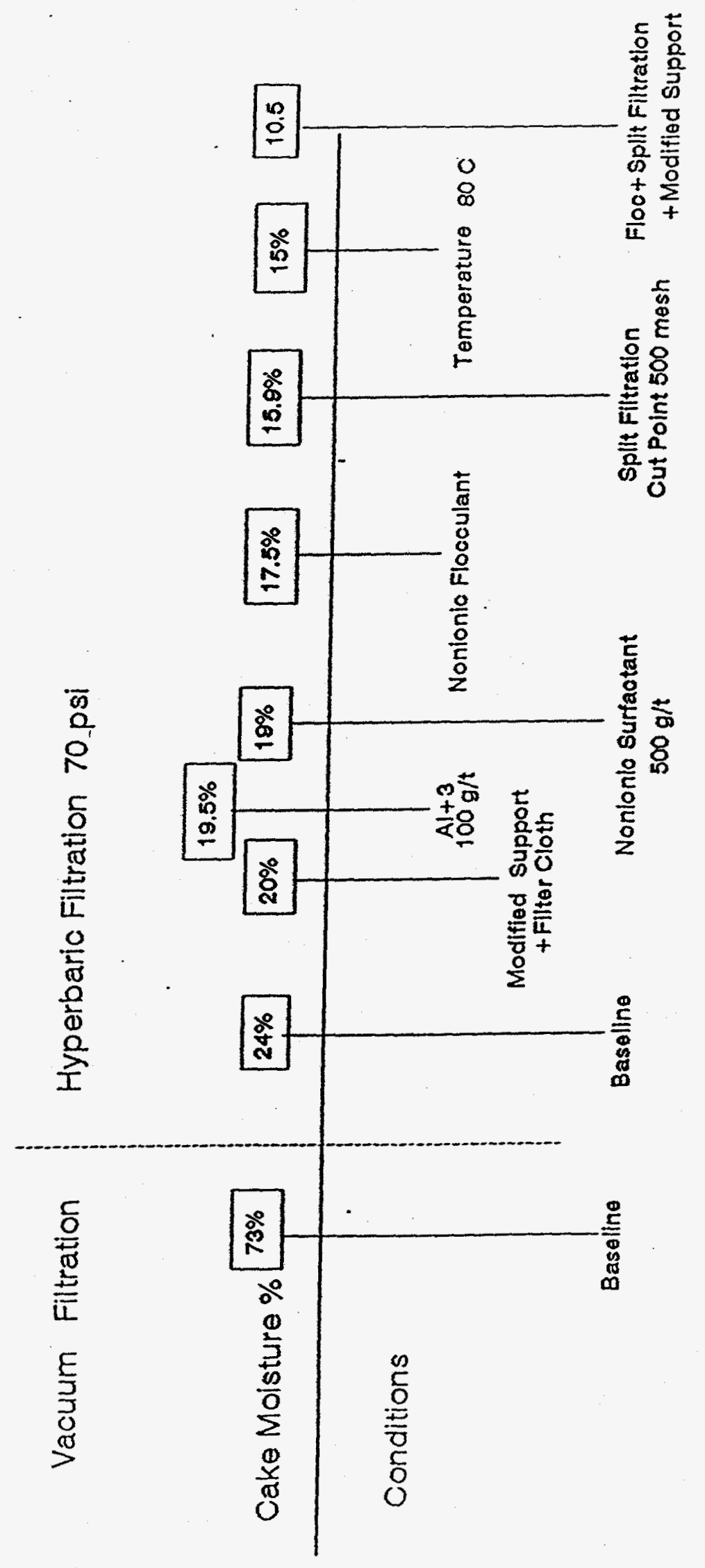

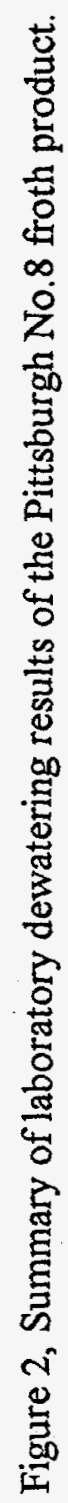




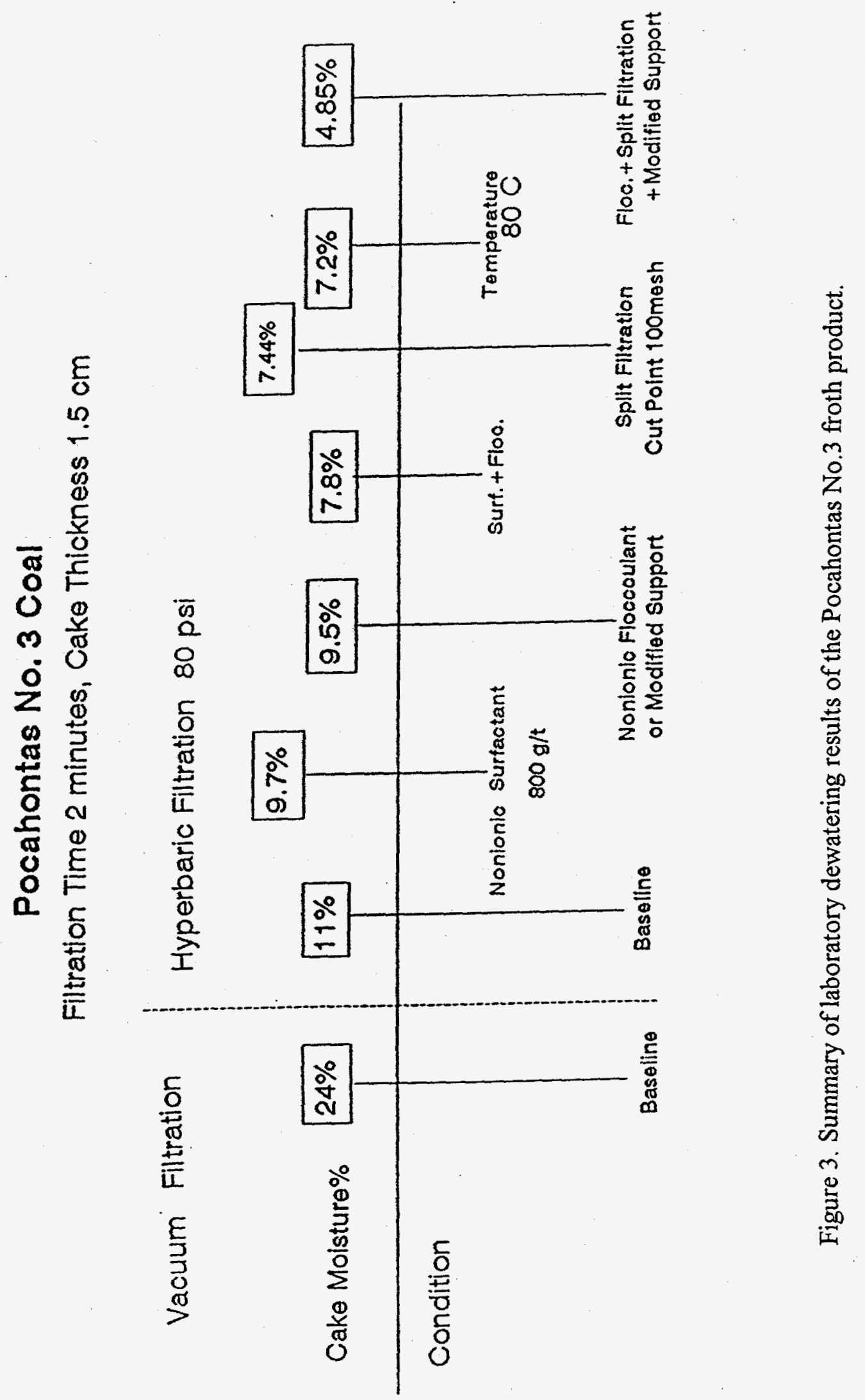




\section{Phase III Pilot Scale Testing:}

The pilot scale hyperbaric filtration(HBF) test results are summarized below:

o For the Pittsburgh seam filter feed material, the HBF using 5 bar applied pressure and 165 degree cake formation angle(CFA) provided 16 percent filter cake moisture.

o Addition of flocculants increased the filter cake moisture. Addition of cationic surfactant lowered filter cake moisture.

o For the Pittsburgh seam flotation feed material using 3.5 bar applied pressure And 85 degree CFA provided 20.5 percent moisture product.

- addition of flocculant increased the moisture content of filter cake, however, It increased the solids throughput in the machine.

- desliming the feed using a cyclone provided a 21.6 percent filter cake moisture.

o For the Pocahontas clean coal slurry, 5 bar applied pressure and 55 degree CFA provided filter cake with 13.5 percent moisture.

- Addition of flocculants increased the filter cake moisture.

- Desliming of the feed did not improve moisture reduction.

\section{FUTURE PLANS}

Submit the final report. 